\title{
FORMAÇÃO CONTINUADA E AUTOPERCEPÇÃO DE COMPETÊNCIA: UM ESTUDO COM TREINADORES DE TÊNIS
}

\section{FORMACIÓN PERMANENTE Y AUTOPERCEPCIÓN DE COMPETENCIA: UN ESTUDIO CON ENTRENADORES DE TENIS}

\section{CONTINUING EDUCATION AND SELF-PERCEPTION OF COMPETENCE: A STUDY WITH TENNIS COACHES}

\author{
Caio Corrêa Cortela ${ }^{1}$, Michel Milistetd ${ }^{2}$, Jorge Both ${ }^{3}$, Larissa Rafaela Galatti ${ }^{4}$, Miguel Crespo ${ }^{5}$, \\ Carlos Adelar Abaide Balbinotti ${ }^{6}$ \\ capacitacao@fpt.com.br; michel.milistetd@ufsc.br; jorgeboth@yahoo.com.br; \\ larissa.galatti@fca.unicamp.br; miguel.crespo@itftennis.com; carlos.balbinotti@ufrgs.br \\ ${ }^{1}$ Federação Paranaense de Tênis ${ }^{2}$ Universidade Federal de Santa Catarina (UFSC) \\ ${ }^{3}$ Universidade Estadual de Londrina (UEL) ${ }^{4}$ Universidade Estadual de Campinas (FCA- \\ UNICAMP) ${ }^{5}$ Federação Internacional de Tênis (ITF) \\ ${ }^{6}$ Universidade Federal do Rio Grande do Sul (UFRGS)
}

Envio Original: 2019-04-15 Reenviado: 2019-09-24 Aceitado: 2019-10-29

Publicado: 2019-11-12

Doi: https://doi.org/10.15517/pensarmov.v17i2.36948

\begin{abstract}
Resumo
Este estudo teve como objetivo associar a formação continuada dos treinadores com a autopercepção e a importância atribuída ao constructo - competência profissional. A amostra foi composta por 69 treinadores de tênis, participantes de ações de capacitação promovidas pela Federação Paranaense de Tênis constituída, majoritariamente, por profissionais: com mais de oito anos de experiência profissional; com experiência como praticante; e graduados em Educação Física. Para recolha de dados utilizou-se uma ficha contendo as variáveis sociodemográficas e a Escala de Autopercepção de Competência. Os resultados indicaram que a participação em atividades/cursos não demonstrou associação significativa com a autopercepção de competência dos treinadores para os Conhecimentos Profissionais. Para a dimensão Habilidades Profissionais, o envolvimento nessas ações relacionou-se significativamente com a autopercepção de domínio, com destaque para as habilidades relacionadas ao Planejamento e Gestão Esportiva, e Avaliação Esportiva, habilidades
\end{abstract}


consideradas centrais no exercício profissional do treinador. A importância atribuída aos Conhecimentos e Habilidades Profissionais foi elevada, sendo sempre superior à autopercepção de domínio.

Palavras-Chave: conhecimento profissional, competências profissionais, formação de treinadores, desenvolvimento profissional.

\title{
Resumen
}

Este estudio tuvo como objetivo asociar la formación permanente de entrenadores con la autopercepción y la importancia atribuida al constructo - competencia profesional. La muestra fueron 69 entrenadores de tenis, que participaron de acciones de capacitación promovidas por la Federación Paranaense de Tenis, estando constituida mayormente por profesionales: con más de ocho años de experiencia profesional; con experiencia como practicante; y graduados en Educación Física. Para la recolección de datos se utilizó una ficha con variables socio demográficas y la Escala de Auto Percepción de Competencia. Los resultados indicaron que la participación en actividades/cursos no tuvo asociación significativa con la autopercepción de competencia de los entrenadores para los Conocimientos Profesionales. Para la dimensión Habilidades Profesionales el involucramiento en esas acciones estuve significativamente relacionado en la autopercepción de dominio, con destaque para las habilidades pariente a la Planificación y Gestión Deportiva y, Evaluación Deportiva, habilidades consideradas centrales en el ejercicio profesional de entrenador. La importancia atribuida a los Conocimientos y Habilidades Profesionales fue elevada, siendo siempre superior a la autopercepción de dominio.

Palabras clave: conocimiento profesional, competencias profesionales, formación de entrenadores, desarrollo profesional.

\begin{abstract}
The aim of this study was to associate the coaches' continuing education and self-perception and the importance attributed to the construct of coaches' professional competence. The sample was 69 tennis coaches, whom have participated in professional training actions promoted by the Paraná Tennis Federation. The characteristics of participants were: more than eight years of professional experience; experience as a tennis player; and graduate level in Physical Education. A chart containing the sociodemographic variables and the Competence Self Perception Scale were used on data collection. The results indicated that participation in workshops / courses did not demonstrate a significant association with the self-perception of competencies for the Professional Knowledge dimension. For the Professional Skills dimension, involvement in these
\end{abstract}


actions was significantly related to self-perception of mastery, with emphasis on skills related to Sports Planning and Sports Management and, Sports Assessment, skills considered as pivotal to the professional coaching intervention. The importance attached to Knowledge and Professional skills was high, always being higher than the self-perception of domain.

Keywords: professional knowledge, professional skills, coaches, coach education, coach development.

\section{Introdução}

A valorização da atividade do treinador esportivo se encontra no período mais dinâmico de sua existência. As exigências dessa profissão evoluíram do simples domínio dos conteúdos técnico/táticos de uma modalidade para a necessidade de demonstrar competência em diversas áreas, tais como a capacidade de se comunicar com qualidade, atuar em diferentes ambientes, refletir sobre a própria prática, entre outros domínios (Milistetd, Galatti, Tozetto, Collet \& Nascimento, 2017).

Apesar do aumento da complexidade do coaching esportivo no século XXI e consequente exigência de qualificação na intervenção do treinador, o reconhecimento do status profissional nessa área ainda é controverso (Taylor \& Garrat, 2013). Em muitos países a atuação como treinador é realizada de modo voluntário, principalmente quando o contexto é de formação ou de participação esportiva (International Council for Coaching Excellence [ICCE], 2013). Todavia, no esporte de rendimento, o número de voluntários é menor, atuando nesse segmento principalmente treinadores remunerados part-time ou full time (Duffy, Petrovic \& Crespo, 2010).

Essa diversidade de ambientes de atuação, aliada a exigência de uma intervenção cada vez mais qualificada, têm demandado melhorias nos processos formativos de treinadores esportivos (ICCE, 2013). Entre os principais avanços apresentados na literatura sobre a formação desses profissionais é possível identificar uma mudança de paradigmas educativos em diferentes países (Ciampolini, Milistetd, Rynne, Brasil \& Nascimento, 2019), com reconhecimento da universidade como um ambiente formativo (Milistetd et al., 2017) e a concepção de que o desenvolvimento do treinador é um processo contínuo que deve ocorrer ao longo de suas carreiras (Trudel \& Gilbert, 2013).

Especificamente no Brasil, em que o treinador esportivo é reconhecido em todos os seus contextos de atuação como um profissional (Governo do Brasil, 1998), o processo de preparação formal ocorre, sobretudo, no ambiente universitário, por meio dos cursos de bacharelado em Educação Física. No entanto, a formação inicial tem se mostrado limitada ao desenvolvimento de 
conhecimentos gerais, com pouca ênfase às competências essenciais para a intervenção do treinador esportivo, tais como: o estabelecimento de uma filosofia de trabalho; estratégias de comunicação e resolução de problemas; e avaliação da própria prática (Milistetd et al., 2017).

Diante disso, a formação continuada assume papel central no desenvolvimento desses profissionais (Rodrigues, Paes \& Souza Neto, 2016). O engajamento em diferentes oportunidades de aprendizagem demonstra impactar diretamente a percepção e a importância atribuída pelos treinadores aos conhecimentos e competências profissionais. De modo geral, os resultados de estudos que investigaram o papel desempenhado pela formação inicial/continuada e da experiência apontam que as mesmas influenciam: na preferência por conteúdos específicos relacionados ao conhecimento profissional (Egerland, Nascimento \& Both, 2009a; Egerland, Nascimento \& Both, 2010); na importância atribuída às competências profissionais (Egerland et al., 2009a; Egerland et al., 2010); e na autopercepção de competência profissional (Egerland, Salles \& Baldi, 2014).

Assim, com base no quadro descrito anteriormente, o presente estudo teve como objetivo principal identificar a existência de possíveis associações entre a formação continuada de treinadores de tênis e a autopercepção e importância atribuída ao constructo - competência profissional. De forma específica, buscou-se relacionar a autopercepção de competência desses profissionais com a importância atribuída aos aspectos que compõem a matriz de análise da competência profissional.

\section{MÉTODOS}

\section{Tipo de Pesquisa e Amostra}

O estudo caracterizou-se como descritivo-exploratório, de corte transversal e de abordagem quantitativa (Silva, Minatto, Fares \& Santos, 2011). A amostra foi composta por treinadores de tênis participantes de ações de formação continuada desenvolvidas pela Federação Paranaense de Tênis (FPT). Dessa forma, participaram do estudo 69 treinadores $(32,6 \pm 9,3$ anos de idade) de ambos os sexos (64 homens e 5 mulheres).

A maior parte do grupo investigado possuía as seguintes características: socialização préprofissional como pegador de bolas (boleiro) (46\%); e nível técnico compatível à primeira ou segunda classe no ranking da FPT, em uma escala de oito classes (56\%). No que se refere à formação inicial e continuada, observou-se que $23 \%$ dos treinadores cursavam Educação Física no momento da coleta, ao passo que $51 \%$ relataram já possuir a graduação nessa área. A maioria (81\%) declarou ter participado de atividades/cursos de formação continuada nos últimos cinco 
anos. Desses, $52 \%$ estiveram presentes em quatro eventos, ou mais. Por fim, destaca-se que $51 \%$ da amostra exerce a profissão de treinador de tênis há mais de oito anos.

\section{Instrumento}

Os instrumentos utilizados para coleta dos dados foram: uma ficha para levantamento de variáveis sociodemográficas (idade, sexo, experiência como praticante e treinador, formação inicial e continuada); e a Escala de Autopercepção de Competência (EAPC) de treinadores esportivos, modificada para a realidade brasileira por (Egerland et al., 2010). A versão modificada da EAPC é composta por 78 questões fechadas, relacionadas à autopercepção de competência e à importância atribuída, sendo organizada em uma estrutura bidimensional, compostas pelas dimensões Conhecimentos Profissionais e Habilidades Profissionais. A dimensão Conhecimento Profissional é composta por 46 itens, pertencentes a quatro categorias: Gestão e Legislação do Esporte; Biodinâmica; Aspectos Psico-socio-culturais do Esporte; e Teoria e Metodologia do Treinamento. Nessa mesma direção, a dimensão Habilidades Profissionais apresenta os seus 32 itens subdivididos em quatro áreas: Avaliação no Esporte; Comunicação e Integração; Planejamento e Gestão Esportiva; Autorreflexão e Atualização Profissional. Por meio de uma escada do tipo Likert de cinco pontos, os treinadores informam o grau de domínio (1=não domino e 5= domino muito bem) e importância atribuída (1= nenhuma importância e 5= importância muito grande), aos itens apresentados.

A adaptação transcultural do instrumento ocorreu em três etapas. Primeiramente realizouse a tradução e adequação de linguagem para o português brasileiro. Na segunda etapa buscouse avaliar a clareza e a objetividade da linguagem, com 26 treinadores participando desse processo, os quais apresentaram índices de consenso iguais ou superiores a $80 \%$, na relação dimensões e itens. Após esses procedimentos foi realizada a avaliação da reprodutibilidade do instrumento com 50 treinadores, em que todas as questões apresentaram índices aceitáveis de concordância, verificando-se valores superiores a 0,75 (Egerland et al., 2010).

\section{Procedimentos de coletas}

As coletas de dados ocorreram presencialmente e com a anuência da FPT, durante a realização de três ações de formação continuada organizadas pela instituição. Essas ações ocorreram em dois clubes e em uma academia de tênis, localizados em três regiões distintas (Região Metropolitana de Curitiba, Oeste Paranaense e Norte Paranaense) do estado do Paraná - Brasil. 
Após serem apresentados os objetivos da pesquisa, os treinadores foram convidados a participar do estudo. Aos profissionais que demonstraram interesse em colaborar com a investigação foram entregues o Termo de Livre Consentimento Esclarecido (TCLE), e os instrumentos a serem respondidos.

\section{Tratamento estatístico}

Ao final do período de coleta, os dados encontrados foram transcritos para uma planilha do software Microsoft Excel, para Windows, especificamente elaborada para essa finalidade. Para categorização dos dados referentes aos conhecimentos e habilidades profissionais, utilizou-se uma versão adaptada da equação de ponderação descrita por Lemos (2007). Valores iguais e abaixo de zero, em uma escala de variabilidade de $-100 a+100$, encontrados para a competência profissional e importância atribuídas, foram categorizados respectivamente como: Não domina e Não Importante. Por outro lado, valores iguais ou superiores a 0,1 foram categorizados como: Domina, para competência profissional; e importante, para importância atribuída.

Posteriormente, na análise estatística dos dados foram realizados cálculos de frequência e estatística descritiva. Para comparações entre os grupos compostos por treinadores que frequentaram e não frequentaram atividades de formação continuada nos últimos cinco anos, no que diz respeito às dimensões Conhecimento e Habilidades Profissionais, e suas subcategorias, foi empregado o teste Qui-quadrado. Nos casos em que as frequências esperadas em uma das caselas das tabelas $(2 \times 2)$ foram menores do que cinco, optou-se pela utilização do teste exato de Fisher. Por sua vez, para comparações entre os resultados apresentados pelo grupo de treinadores para as variáveis, competência percebida e importância atribuída, utilizou-se o teste McNemar. Para todas as análises foi pré-estabelecido o nível de significância com $p \leq 0,05$.

\section{RESULTADOS}

Em relação à análise do constructo das competências profissionais, a amostra de treinadores relatou baixo índice de domínio apenas no indicador Gestão e Legislação do Esporte $(37,7 \%)$. Para a maior parte das dimensões e categorias analisadas os valores encontrados foram considerados razoáveis: Conhecimentos (58,0\%) e Habilidades Profissionais (63,8\%); Avaliação Global da Competência Profissional (52,2\%); Avaliação no Esporte (62,3\%); Biodinâmica do Esporte (66,7\%); e Autorreflexão e Atualização Profissional no Esporte (68,1\%). Por fim, elevados índices de competência profissional foram evidenciados nos indicadores: Planejamento e Gestão 
Esportiva (71,0\%); Comunicação e Integração (73,9\%); Psico-Sócio-Culturais do Esporte (76,8\%); Teoria e Metodologia do Treinamento Esportivo (82,6\%) (Tabela 1).

Tabela 1.

Associação entre autopercepção de domínio de competência profissional e realização de cursos de formação continuada em treinadores de tênis.

\begin{tabular}{|c|c|c|c|}
\hline Formação Continuada & Competência & percebida & \\
\hline DIMENSÃO - Conhecimentos Profissionais & Não Domina & Domina & p \\
\hline Avaliação Global - Conhecimentos Profissionais ${ }^{1}$ & & & 0,34 \\
\hline Não frequentou & $7(53,8 \%)$ & $6(46,2 \%)$ & \\
\hline Frequentou & $22(39,3 \%)$ & $34(60,7 \%)$ & \\
\hline Total & $29(42,0 \%)$ & $40(58,0 \%)$ & \\
\hline Gestão e Legislação do Esporte ${ }^{2}$ & & & 0,06 \\
\hline Não frequentou & $11(84,6 \%)$ & $2(15,4 \%)$ & \\
\hline Frequentou & $32(57,1 \%)$ & $24(42,9 \%)$ & \\
\hline Total & $43(62,3 \%)$ & $26(37,7 \%)$ & \\
\hline Biodinâmica do Esporte $^{2}$ & & & 0,55 \\
\hline Não frequentou & $4(30,8 \%)$ & $9(69,2 \%)$ & \\
\hline Frequentou & $19(33,9 \%)$ & $37(66,1 \%)$ & \\
\hline Total & $23(33,3 \%)$ & $46(66,7 \%)$ & \\
\hline Psico-Sócio-Culturais do Esporte ${ }^{2}$ & & & 0,35 \\
\hline Não frequentou & $4(30,8 \%)$ & $9(69,2 \%)$ & \\
\hline Frequentou & $12(21,4 \%)$ & $44(78,6 \%)$ & \\
\hline Total & $16(23,2 \%)$ & $53(76,8 \%)$ & \\
\hline Teoria e Metodologia do Treinamento Esportivo ${ }^{2}$ & & & 0,16 \\
\hline Não frequentou & $4(30,8 \%)$ & $9(69,2 \%)$ & \\
\hline Frequentou & $8(14,3 \%)$ & $48(85,7 \%)$ & \\
\hline Total & $12(17,4 \%)$ & $57(82,6 \%)$ & \\
\hline DIMENSÃO - Habilidades Profissionais & Não Domina & Domina & $\mathbf{p}$ \\
\hline Avaliação Global - Habilidades Profissionais ${ }^{2}$ & & & $0,04^{*}$ \\
\hline Não frequentou & $8(61,5 \%)$ & $5(38,5 \%)$ & \\
\hline Frequentou & $17(30,4 \%)$ & $39(69,6 \%)$ & \\
\hline Total & $25(36,2 \%)$ & $44(63,8 \%)$ & \\
\hline Planejamento e Gestão Esportiva ${ }^{2}$ & & & $<0,01^{*}$ \\
\hline Não frequentou & $8(61,5 \%)$ & $5(38,5 \%)$ & \\
\hline Frequentou & $12(21,4 \%)$ & $44(78,6 \%)$ & \\
\hline Total & $20(29,0 \%)$ & $49(71,0 \%)$ & \\
\hline Avaliação no Esporte ${ }^{2}$ & & & $0,05^{*}$ \\
\hline Não frequentou & $8(61,5 \%)$ & $5(38,5 \%)$ & \\
\hline Frequentou & $18(32,1 \%)$ & $38(67,9 \%)$ & \\
\hline Total & $26(37,7 \%)$ & $43(62,3 \%)$ & \\
\hline
\end{tabular}




\begin{tabular}{lccc}
\hline Comunicação e Integração $^{2}$ & & 0,07 \\
Não frequentou & $6(46,2 \%)$ & $7(53,8 \%)$ & \\
Frequentou & $12(21,4 \%)$ & $44(78,6 \%)$ & \\
Total & $18(26,1 \%)$ & $51(73,9 \%)$ & \\
\hline Autorreflexão e Atualização Profissional no Esporte ${ }^{2}$ & & & 0,06 \\
Não frequentou & $7(53,8 \%)$ & $6(46,2 \%)$ & \\
Frequentou & $15(26,8 \%)$ & $41(73,2 \%)$ & \\
Total & $22(31,9 \%)$ & $47(68,1 \%)$ & \\
\hline AVALIAÇÃO GLOBAL & Não Domina & Domina & p \\
\hline Competência Percebida ${ }^{1}$ & & & 0,09 \\
Não frequentou & $9(69,2 \%)$ & $4(30,8 \%)$ & \\
Frequentou & $24(42,9 \%)$ & $32(57,1 \%)$ & \\
Total & $33(47,8 \%)$ & $36(52,2 \%)$ & \\
\hline
\end{tabular}

Legenda: (1) Qui-quadrado; (2) Exato de Fisher; ( ${ }^{*}$ ) Diferença Significativa.

FONTE: Elaborada pelos autores.

Ao analisar a relação existente entre formação continuada e competência profissional (Tabela 1), observou-se que os treinadores que frequentaram cursos de formação nos últimos cinco anos apresentaram índices mais elevados de domínio nos indicadores Planejamento e Gestão Esportiva $(p<0,01)$, Avaliação no Esporte $(p=0,05)$ e na dimensão Habilidades Profissionais $(p=0,04)$.

Sobre a importância atribuída pelos treinadores às unidades que compõem o constructo da competência profissional, observou-se que todos os indicadores, dimensões e avaliação global apresentaram elevados índices de importância (entre 79,7\% e 94,2\%) (Tabela 2).

Tabela 2.

Associação entre importância atribuída do constructo da competência profissional e realização de atividades/cursos de formação continuada em treinadores de tênis.

\begin{tabular}{lccc}
\hline \multicolumn{1}{c}{ Formação Continuada } & \multicolumn{2}{c}{ Importância atribuída } \\
\hline DIMENSÃO - Conhecimentos Profissionais & Não Importante & Importante & p \\
\hline Avaliação Global - Conhecimentos Profissionais & & & 0,17 \\
Não frequentou & $3(23,1 \%)$ & $10(76,9 \%)$ & \\
Frequentou & $5(8,9 \%)$ & $51(91,1 \%)$ & \\
Total & $8(11,6 \%)$ & $61(88,4 \%)$ & \\
\hline Gestão e Legislação do Esporte ${ }^{1}$ & & & $0,02^{*}$ \\
Não frequentou & $6(46,2 \%)$ & $7(53,8 \%)$ & \\
Frequentou & $8(14,3 \%)$ & $48(85,7 \%)$ & \\
Total & $14(20,3 \%)$ & $55(79,7 \%)$ & \\
\hline
\end{tabular}




\begin{tabular}{|c|c|c|c|}
\hline Biodinâmica do Esporte ${ }^{2}$ & & & 0,69 \\
\hline Não frequentou & $1(7,7 \%)$ & $12(92,3 \%)$ & \\
\hline Frequentou & $5(8,9 \%)$ & $51(91,1 \%)$ & \\
\hline Total & $6(8,7 \%)$ & $63(91,3 \%)$ & \\
\hline Psico-Sócio-Culturais do Esporte ${ }^{2}$ & & & 0,39 \\
\hline Não frequentou & $2(15,4 \%)$ & $11(84,6 \%)$ & \\
\hline Frequentou & $5(8,9 \%)$ & $51(91,1 \%)$ & \\
\hline Total & $7(10,1 \%)$ & $62(89,9 \%)$ & \\
\hline $\begin{array}{llll}\text { Teoria e } & \text { Metodologia } & \text { do } & \text { Treinamento } \\
\text { Esportivo }^{2} & & & \end{array}$ & & & 0,43 \\
\hline Não frequentou & $0(0 \%)$ & $13(100 \%)$ & \\
\hline Frequentou & $4(7,1 \%)$ & $52(92,9 \%)$ & \\
\hline Total & $4(5,8 \%)$ & $65(94,2 \%)$ & \\
\hline DIMENSÃO - Habilidades Profissionais & Não Importante & Importante & $\mathbf{p}$ \\
\hline Avaliação Global - Habilidades Profissionais ${ }^{2}$ & & & 0,39 \\
\hline Não frequentou & $2(15,4 \%)$ & $11(84,6 \%)$ & \\
\hline Frequentou & $5(8,9 \%)$ & $51(91,1 \%)$ & \\
\hline Total & $7(10,1 \%)$ & $62(89,9 \%)$ & \\
\hline Planejamento e Gestão Esportiva ${ }^{2}$ & & & 0,32 \\
\hline Não frequentou & $2(15,4 \%)$ & $11(84,6 \%)$ & \\
\hline Frequentou & $4(7,1 \%)$ & $52(92,9 \%)$ & \\
\hline Total & $6(8,7 \%)$ & $63(91,3 \%)$ & \\
\hline Avaliação no Esporte ${ }^{2}$ & & & 0,47 \\
\hline Não frequentou & $2(15,4 \%)$ & $11(84,6 \%)$ & \\
\hline Frequentou & $6(10,7 \%)$ & $50(89,3 \%)$ & \\
\hline Total & $8(11,6 \%)$ & $61(88,4 \%)$ & \\
\hline Comunicação e Integração & & & 0,58 \\
\hline Não frequentou & $1(7,7 \%)$ & $12(92,3 \%)$ & \\
\hline Frequentou & $3(5,4 \%)$ & $53(94,6 \%)$ & \\
\hline Total & $4(5,8 \%)$ & $65(94,2 \%)$ & \\
\hline $\begin{array}{l}\text { Autorreflexão e Atualização Profissional no } \\
\text { Esporte }\end{array}$ & & & 0,28 \\
\hline Não frequentou & $3(23,1 \%)$ & $10(76,9 \%)$ & \\
\hline Frequentou & $7(12,5 \%)$ & $49(87,5 \%)$ & \\
\hline Total & $10(14,5 \%)$ & $59(85,5 \%)$ & \\
\hline AVALIAÇÃO GLOBAL & Não Importante & Importante & p \\
\hline Importância Atribuída $^{1}$ & & & 0,22 \\
\hline Não frequentou & $3(23,1 \%)$ & $10(76,9 \%)$ & \\
\hline Frequentou & $6(10,7 \%)$ & $50(89,3 \%)$ & \\
\hline Total & $9(13,0 \%)$ & $60(87,0 \%)$ & \\
\hline
\end{tabular}

Legenda: (1) Qui-quadrado; (2) Exato de Fisher; ( ${ }^{*}$ ) Diferença Significativa.

FONTE: Elaborada pelos autores. 
A importância atribuída aos assuntos evidenciados no constructo da competência profissional e a realização de curso de formação continuada apresentaram associação significativa apenas para o indicador Gestão e Legislação do Esporte $(p=0,02)$ (Tabela 2), sendo que os resultados evidenciaram que o grupo de treinadores que frequentou cursos de formação continuada nos últimos anos apresentou índice mais elevado de importância atribuída (85,7\%) que os treinadores que não participaram (53,8\%).

Ao comparar a relação existente entre a autopercepção de domínio e de importância atribuída da competência profissional, observou-se que em todos os indicadores, dimensões e avaliação global do constructo da competência profissional evidenciaram diferenças significativas (valor de $p<0,01$ ou $<0,05$ ) (Tabela 3).

Tabela 3.

Relação entre autopercepção de domínio e importância atribuída das competências profissionais dos treinadores de tênis.

\begin{tabular}{|c|c|c|c|c|c|}
\hline $\begin{array}{l}\text { Competências } \\
\text { Profissionais }\end{array}$ & $\begin{array}{c}\text { Não } \\
\text { domina e } \\
\text { não julga } \\
\text { importante }\end{array}$ & $\begin{array}{c}\text { Não } \\
\text { domina e } \\
\text { julga } \\
\text { importante }\end{array}$ & $\begin{array}{c}\text { Domina e } \\
\text { não julga } \\
\text { importante }\end{array}$ & $\begin{array}{c}\text { Domina e } \\
\text { julga } \\
\text { importante }\end{array}$ & $\mathbf{P}$ \\
\hline \multicolumn{6}{|c|}{ DIMENSÃO - Conhecimentos Profissionais } \\
\hline $\begin{array}{l}\text { Avaliação Global - } \\
\text { Conhecimentos Profissionais }\end{array}$ & $6(8,7 \%)$ & $23(33,3 \%)$ & $2(2,9 \%)$ & $38(55,1 \%)$ & $<0,01^{*}$ \\
\hline $\begin{array}{l}\text { Gestão e Legislação do } \\
\text { Esporte }\end{array}$ & $12(17,4 \%)$ & $31(44,9 \%)$ & $2(2,9 \%)$ & $24(34,8 \%)$ & $<0,01^{*}$ \\
\hline Biodinâmica do Esporte & $5(7,2 \%)$ & $18(26,1 \%)$ & $1(1,4 \%)$ & $45(65,2 \%)$ & $<0,01^{*}$ \\
\hline $\begin{array}{l}\text { Aspectos Psico-Sócio- } \\
\text { Culturais do Esporte }\end{array}$ & $3(4,3 \%)$ & $13(18,8 \%)$ & $4(5,8 \%)$ & $49(71,0 \%)$ & $0,05^{*}$ \\
\hline $\begin{array}{l}\text { Teoria e Metodologia do } \\
\text { Treinamento Esportivo }\end{array}$ & $3(4,3 \%)$ & $9(13,0 \%)$ & $1(1,4 \%)$ & $56(81,2 \%)$ & $0,02^{*}$ \\
\hline \multicolumn{6}{|c|}{ DIMENSÃO - Habilidades Profissionais } \\
\hline $\begin{array}{l}\text { Avaliação Global - } \\
\text { Habilidades Profissionais }\end{array}$ & $5(7,2 \%)$ & $20(29,0 \%)$ & $2(2,9 \%)$ & $42(60,9 \%)$ & $<0,01^{*}$ \\
\hline $\begin{array}{l}\text { Planejamento e Gestão } \\
\text { Esportiva }\end{array}$ & $5(7,2 \%)$ & $15(21,7 \%)$ & $1(1,4 \%)$ & $48(69,6 \%)$ & $<0,01^{*}$ \\
\hline Avaliação no Esporte & $4(5,8 \%)$ & $22(31,9 \%)$ & $4(5,8 \%)$ & $39(56,5 \%)$ & $<0,01^{*}$ \\
\hline $\begin{array}{l}\text { Comunicação e Integração } \\
\text { no Esporte }\end{array}$ & $4(5,8 \%)$ & $14(20,3 \%)$ & $0(0 \%)$ & $51(73,9 \%)$ & $<0,01^{*}$ \\
\hline $\begin{array}{l}\text { Autorreflexão e Atualização } \\
\text { Profissional no Esporte }\end{array}$ & $6(8,7 \%)$ & $16(23,2 \%)$ & $4(5,8 \%)$ & $43(62,3 \%)$ & $<0,01^{*}$ \\
\hline
\end{tabular}




\begin{tabular}{llllll}
\hline Avaliação Global & $8(11,8 \%)$ & $25(36,2 \%)$ & $1(1,4 \%)$ & $35(50,7 \%)$ & $<0,01^{*}$ \\
\hline
\end{tabular}

Legenda: Teste de McNemar; $\left(^{*}\right)$ Diferença Significativa.

FONTE: Elaborada pelos autores.

O índice de desinteresse evidenciado pela amostra (Tabela 3), ou seja, declarar que não julga importante, mas domina os assuntos abordados no constructo sobre a competência profissional, foi baixo, com os escores dos indicadores, dimensões e avaliação global chegando ao máximo de 5,8\%. Além disso, destaca-se que o índice de concordância entre o fato de não dominar e não julgar importante as questões abordadas no constructo da competência profissional, apresentou valor expressivo apenas no indicador Gestão e Legislação do Esporte $(17,4 \%)$.

O nível de concordância entre o fato de dominar e julgar importante evidenciou grande variação no constructo da competência profissional (Tabela 3). Os indicadores: Aspectos PsicoSócio-Culturais do Esporte (71,0\%), Teoria e Metodologia do Treinamento Esportivo (81,2\%) e Comunicação e Integração $(73,9 \%)$ apresentaram os maiores índices de treinadores que possuem domínio e atribuem importância a esses assuntos. Por outro lado, apenas o indicador Gestão e Legislação do Esporte evidenciou baixo índice de treinadores que possuem domínio e atribuem importância a esse assunto (34,8\%).

O percentual de treinadores que se julgaram com baixo domínio, mas que entendem que os assuntos abordados no constructo da competência profissional são importantes variou entre 13,0\% e 44,9\%. Destaca-se que, no mínimo, um quarto da amostra relatou a necessidade de ter maior domínio na Avaliação Global da Competência Profissional, nas dimensões Conhecimentos e Habilidades Profissionais e nos indicadores Gestão e Legislação do Esporte, Avaliação no Esporte, Biodinâmica do Esporte. Entretanto, o indicador que os treinadores evidenciaram maior necessidade de domínio foi Teoria e Metodologia do Treinamento Esportivo.

\section{DISCUSSÃO}

A análise geral dos dados encontrados para a dimensão Conhecimento Profissional demonstrou estar em conformidade com os resultados descritos pela literatura para treinadores esportivos, em que os saberes relacionados às categorias Teoria e Metodologia do Treinamento, aos Aspectos Psico-socioculturais do Esporte, e a Biodinâmica, respectivamente nessa ordem, apresentaram maior autopercepção de domínio (Egerland et al., 2010; Egerland, Salles, Barroso, Baldi \& Do Nascimento, 2013; Egerland et al., 2014). Mesmo encontrando-se essa similaridade, diferenças substanciais foram observadas no percentual de treinadores que relataram dominar 
esses conhecimentos, com os treinadores da amostra apresentando maior criticidade sobre a autopercepção de competência. Essa característica não parece ser uma particularidade dos treinadores de tênis, uma vez que foi observada em outros estudos com profissionais de outras modalidades individuais (Egerland et al., 2010; Egerland et al., 2014).

A verificação de que $33 \%$ da amostra afirmou não dominar os conhecimentos relativos à categoria Biodinâmica, alerta para a necessidade de uma maior atenção, por parte das instituições responsáveis por auxiliar o desenvolvimento desses profissionais (universidades, confederações, federações, entre outras), e de um monitoramento constante quanto às necessidades e expectativas referentes à aprendizagem profissional. Os saberes envolvidos nessa categoria fazem parte do cotidiano dos treinadores de tênis, independentemente do contexto de atuação profissional (participação ou rendimento) (Egerland et al., 2009a). Nela se encontram inseridos os conhecimentos relativos ao desenvolvimento e às capacidades motoras, sobre nutrição, biomecânica e fisiologia aplicadas ao esporte (Egerland et al., 2010).

Em âmbito internacional a formação de treinadores ocorre por meio de três vias distintas: a federativa (Federação Internacional de Tênis - ITF ou pelas confederações e federações); a universitária ou acadêmica, ofertada por instituições de ensino superior; e as formações ministradas por associações privadas (Fuentes \& Villar, 2004). Entre essas, as formações de cunho federativo são as mais frequentadas pelos treinadores de tênis em todo o mundo. Em geral, as titulações expedidas nesse âmbito apresentam-se divididas em três ou quatro módulos, sendo que as cargas horárias, os pré-requisitos e os conteúdos de cada módulo variam de um país para outro (Fuentes \& Villar, 2004).

Segundo Sanz, Fuentes e Villar (2004) as nações em desenvolvimento na modalidade, como é o caso dos países latino-americanos, costumam optar pelo modelo de formação estabelecido pela ITF. Esse currículo com caráter generalista é composto por três níveis de formação: um primeiro destinado ao trabalho com tenistas iniciantes ou com nível intermediário de jogo; o segundo voltado à tenistas avançados; e último nível orientado aos treinadores interessados em trabalhar com tenistas de alto rendimento; onde os conhecimentos profissionais requeridos com maior frequência pelos treinadores são abordados com maior profundidade ao longo do processo.

Particularmente, os conhecimentos relativos à Biodinâmica aparecem com frequência durante o processo de formação (ITF, 2014). Nesse sentido, o fato de não terem sido encontradas associações estatisticamente significativas entre a participação em cursos/atividades de formação continuada e a autopercepção de competência para os conhecimentos profissionais, reforça a complexidade do processo de aprendizagem, e sucinta a realização de estudos mais 
aprofundados sobre as especificidades dos treinadores de tênis. Pesquisas recentes têm questionado o impacto das formações pontuais de curta duração na aprendizagem profissional de treinadores esportivos (Trudel, Gilbert \& Werthner, 2010). A forma superficial com a qual os conhecimentos e competências são abordados, as estratégias empregadas e a ausência de um currículo estruturado que auxilie os treinadores no processo de construção de uma identidade profissional inovadora, são alguns dos pontos de críticas a esse tipo de formação (Milistetd et al., 2016, Stoszkowski \& Collins, 2016).

Outro fator importante ainda precisa ser considerado. As fontes de aprendizagem dos treinadores são muito variadas, o que possibilita aos treinadores que não participam de ações de formação continuada, seguirem se desenvolvendo por outros meios. Treinadores esportivos, em geral, creditam maior significado às situações não mediadas (Mesquita, Ribeiro, Santos \& Morgan, 2014), ocorridas em contexto informal (Stoszkowski \& Collins, 2016; Walker, Thomas \& Driska, 2018). No caso específico dos treinadores de tênis brasileiros, a formação do profissional encontra-se intimamente ligada à socialização pré-profissional como pegador de bolas (Cortela, Aburachid, Souza, Cortela \& Fuentes García, 2013; Leite, Cieslak, Silva, Balbinotti \& Cortela, 2016). Essa particularidade da realidade nacional se aproxima, muitas vezes, da ideia de "Escola de Ofício" apresentada por Drigo, Souza Neto, Cesana e Gomes Tojal (2011), em que os saberes necessários ao exercício profissional são adquiridos por meio da aprendizagem experiencial e do contato direto com um treinador mais experiente. Tal comportamento favorece o aparecimento de oportunidades de aprendizagem ocorridas por meio de situações não mediadas e em contexto informal.

No que diz respeito ao domínio das habilidades profissionais, os resultados encontrados demonstraram conformidade com os apresentados pela literatura, com as habilidades de Planejamento e Gestão Esportiva, Comunicação e Integração, Avaliação no Esporte, e Autorreflexão e Atualização Profissional, nessa ordem, sendo relatadas com as de maior domínio (Egerland, Nascimento \& Both, 2009b; Egerland et al., 2013; Egerland et al., 2014). Assim como observado para os conhecimentos profissionais, os treinadores de tênis da amostra apresentaram-se mais críticos com relação à percepção de domínio, o que reforça a necessidade de estudos contextualizados para a elaboração das ações de formação continuada.

O envolvimento em atividades de formação continuada se mostrou eficaz na autopercepção de domínio para dimensão Habilidades Profissionais e nos indicadores Planejamento e Gestão Esportiva e Avaliação no Esporte. Segundo Instituto Portugués do Desporto e Juventude (2016) a atividade do treinador ocorre em um ciclo ininterrupto de planejar, aplicar e avaliar as sessões de treino. Essas habilidades estão enquadradas no rol de competências centrais para o exercício 
dos treinadores, estabelecidos pelo ICCE (2013), sendo consideradas pré-requisito para se atingir os domínios mais elevados como profissional. Nesse sentido, observa-se que a participação em ações de formação continuada apresenta-se como uma importante oportunidade de aprendizagem, podendo auxiliar os treinadores de tênis no desenvolvimento de habilidades fundamentais para o desempenho de suas funções.

Assim como constatado em outros estudos (Egerland et al., 2009a; Egerland et al., 2009b; Egerland et al., 2013) observou-se que a importância atribuída aos conhecimentos e habilidades profissionais foi elevada. Nessa mesma direção, verificou-se que a importância atribuída foi sempre superior ao domínio apresentado, apontando lacunas e pontos de melhoria para o desenvolvimento de ações de formação continuada. Os conhecimentos profissionais relativos à categoria Gestão e Legislação Esportiva receberam a menor atribuição de importância. Tal índice pode estar associado à falta de domínio do componente (Tabelas 1 e 2), e/ou menor importância desse conhecimento para o contexto de atuação profissional do grupo em questão.

Associações estatisticamente significativas foram encontradas entre a autopercepção de importância sobre os conhecimentos de Gestão e Legislação Esportiva e a participação em atividades de formação continuada, indicando que os treinadores que se engajam nesse tipo de capacitação tendem a atribuir maior valorização. Nessa categoria encontram-se inseridos os saberes relativos à Gestão e organização, Legislação básica, Doping e Funções diretivas (Egerland et al., 2010). A maior importância conferida pelos treinadores de tênis com formação reflete a preocupação desses profissionais em seguir se desenvolvendo em diferentes áreas do conhecimento. Mesmo para esse grupo, a autopercepção de domínio apresentou-se abaixo do esperado, verificando-se que menos da metade dos profissionais relataram dominar esses conhecimentos. A análise curricular das formações mais frequentadas pelos treinadores permite afirmar que as temáticas ligadas à gestão e legislação não fazem parte do escopo do programa (Confederação Brasileira de Tênis [CBT], 2017), posição essa que pode ser revista em função dos resultados observados.

Os dados apresentados na Tabela 3 apontam o quadro geral sobre as competências e necessidades dos treinadores de tênis, indicando possibilidades de avanços para a reestruturação de programas de formação continuada que possam melhor atender esses profissionais. Dentro dos conhecimentos profissionais os saberes relacionados à Gestão e Legislação Esportiva e, Biodinâmica do Esporte foram identificados como pontos a serem mais bem explorados dentro dos programas, tendo em vista o percentual de treinadores que relataram não dominar, mas julgaram importantes esses conhecimentos. Nessa mesma direção, os resultados observados para as habilidades de Avalição Esportiva também requerem maior 
atenção, devido à importância dessa habilidade para o exercício profissional do treinador de tênis (Instituto Portugués do Desporto e Juventude, 2016; ICCE, 2013).

\section{Considerações finais}

Em notas conclusivas observa-se a necessidade de um novo olhar sobre o impacto das atividades de formação continuada pontuais na autopercepção de competência profissional dos treinadores de tênis. Respondendo aos objetivos propostos para o estudo, os resultados encontrados apontam que a participação em cursos/atividades de formação continuada, desenvolvidos no contexto não formal, não demonstrou associação significativa com a autopercepção de competência desses treinadores, no que diz respeito aos Conhecimentos Profissionais. Por outro lado, essas capacitações relacionaram-se significativamente com a autopercepção de domínio na dimensão Habilidades Profissionais e para as categorias Planejamento/Gestão Esportiva e Avaliação Esportiva, duas habilidades consideradas centrais no exercício profissional do treinador.

A importância atribuída aos conhecimentos e habilidades profissionais, de modo geral, foi elevada, com os treinadores que participaram de formações creditando maior importância aos conhecimentos relativos à Gestão e Legislação Esportiva. Essa categoria de conhecimento foi a que apresentou os maiores contrastes com relação à autopercepção de domínio e importância atribuída. Por sua vez, as habilidades relativas à Avaliação no Esporte demonstraram ser as mais almejadas pelos treinadores que não dominam, mas atribuem importância ao indicador.

A verificação de que a participação em cursos não demonstrou associação significativa com a autopercepção de domínio para os Conhecimentos Profissionais, reforça o caráter individual da aprendizagem e a necessidade de estudos contextualizados para intervenções mais assertivas no desenvolvimento profissional dos treinadores. Por serem considerados os conhecimentos especializados do coaching esportivo, esses conhecimentos têm sido a base dos programas de formação de treinadores, o que suscita a realização de uma análise pormenorizada dos currículos e das estratégias de ensino empregadas nessas ações de formação continuada.

\section{AGRADECIMENTOS}

Os autores agradecem aos treinadores que participaram do estudo e o suporte oferecido pela Federação Paranaense de Tênis. 


\section{REFERÊNCIAS}

Ciampolini, V., Milistetd, M., Rynne, S., Brasil, V.Z. \& Nascimento, J.V. (2019). Research review on coaches' perceptions regarding the teaching strategies experienced in coach education programs. International Journal of Sports Science \& Coaching, 14(2), 216228. doi: https://doi.org/10.1177/1747954119833597

Confederação Brasileira de Tênis [CBT]. (2017). Estrutura dos Cursos de formação oferecidos pelo Departamento de Capacitação. Recuperado de http://cbttenis.com.br/capacitacao.php?cod=3

Cortela, C.C., Aburachid, L.M., Souza, S.P., Cortela, D.N.R. \& Fuentes García, J.P. (2013). A formação inicial e continuada dos treinadores paranaenses de tênis. Conexões: Educação Física, Esporte e Saúde, 11(2), 60-84. doi: https://doi.org/10.20396/conex.v11ii2.8637617

Drigo, A.J., Souza Neto, S., Cesana, J. \& Gomes Tojal, J.B.A. (2011). Artes marciais, formação profissional e escolas de ofício: Análise documental do judô brasileiro. Motricidade, 7(4), 49-62. Recuperado de https://bit.ly/2Nwp9kS

Duffy, P., Petrovic, L. \& Crespo, M. (2010). The European framework for the recognition of coaching competence and qualifications - implications for the sport of athletics in Europe: a report to European Athletics. New Studies in Athletics, 25(1), 27-41. Recuperado de https://www.iaaf.org/nsa/article/filter?\&articleTitle=the\%20european\%20framework\&yea $r=2010$

Egerland, E.M., Do Nascimento, J.V. \& Both, J. (2009a). Professional competences of sports couches of santa catarina state. Motriz. Journal of Sports of Physical Education, 15(4), 890-899.

Recuperado

de http://www.periodicos.rc.biblioteca.unesp.br/index.php/motriz/article/view/2946

Egerland, E.M., Nascimento, J.V. \& Both, J. (2009b). Nível de associação entre a importância atribuída e a competência percebida de treinadores esportivos. Pensar a Prática, 12(3), 1-13. doi: https://doi.org/10.5216/rpp.v12i3.7621

Egerland, E.M., Nascimento, J.V. \& Both, J. (2010). Competência profissional percebida de treinadores esportivos catarinenses. Journal of Physical Education, 21(3), 457-467. doi: https://doi.org/10.4025/reveducfis.v21i3.8285

Egerland, E.M., Salles, W.D.N., Barroso, M.L.C., Baldi, M.F. \& Do Nascimento, J.V. (2013). Potencialidades e necessidades profissionais na formação de treinadores desportivos. 
Revista Brasileira de Ciência e Movimento, 21(2), 31-38. doi: http://dx.doi.org/10.18511/0103-1716/rbcm.v21n2p31-38

Egerland, E., Salles, W.N. \& Baldi, M.F. (2014). Perception of professional competence of Brazilian college coaches. Revista Brasileira de Cineantropometria \& Desempenho Humano, 16(4), 437-446. doi: http://dx.doi.org/10.5007/1980-0037.2014v16n4p437

Fuentes, J.P.G. \& Villar, F.A. (2004). El entrenador de tenis de alto rendimento: un estudio sobre su formación inicial y permanente. Badajoz: APROSUBA -3.

Governo do Brasil (1998). Lei 9.696, 1 de setembro de 1998. Recuperado de http://www.planalto.gov.br/ccivil_03/leis/19696.htm

International Council for Coaching Excellence [ICCE]. (2013). International Sport Coaching Framework Version 1.2. Illinois: Human Kinetics; Champaign. Recuperado de https://www.icce.ws/_assets/files/iscf-1.2-10-7-15.pdf

Instituto Portugués do Desporto e Juventude. (2016). Didática do desporto. In O. Coelho. Plano nacional de formação de treinadores: manuais de formação Grau I (pp. 1-27). Lisboa: Instituto Português de Desporto e Juventude.

International Tennis Federation [ITF]. (2014). Coach education programme. Recuperado de http://en.coaching.itftennis.com/coach-education/coach-education-programme.aspx

Leite, E.V., Cieslak, F., Silva, C.F., Balbinotti, C.A.A. \& Cortela, C.C. (2016). Qualidade de vida, percepção de imagem corporal e aspectos de sonolência em treinadores de tênis de Campo Grande. Revista Brasileira de Qualidade de Vida, 8(2), 175-190. doi: https://doi.org/10.3895/rbqv.v8n2.3881

Lemos, C.A.F. (2007). Qualidade de vida da carreira profissional de professores de Educação Física do magistério público estadual/Rs (Dissertação de mestrado). Universidade Federal de Santa Catarina, Programa de Pós-graduação em Educação Física, Florianópolis, Brasil. Recuperada de http://repositorio.ufsc.br/xmlui/handle/123456789/89948

Mesquita, I., Ribeiro, J., Santos, S. \& Morgan, K. (2014). Coach, learning and coach education: A Portuguese expert coaches' perspective. The Sport Psychologist, 28(2), 124-136. doi: https://doi.org/10.1123/tsp.2011-0117

Milistetd, M., Ciampolini, V., Salles, W.N., Ramos, V., Galatti, L.R. \& Do Nascimento, J.V. (2016). A. Coaches' development in Brazil: structure of sports organizational programs. Sports Coaching Review, 5(2), 1-13. doi: https://doi.org/10.1080/21640629.2016.1201356

Milistetd, M., Galatti, L.R, Tozetto, A., Collet, C. \& Do Nascimento, J.V. (2017). Formação de treinadores esportivos: orientações para a organização das práticas pedagógicas nos 
cursos de bacharelado em educação física, Journal of Physical Education, 28, 1-14. doi: https://doi.org/10.4025/jphyseduc.v28i1.2849

Rodrigues, H.A, Paes, R.R. \& Souza Neto, S. (2016). A socialização profissional do treinador esportivo como um processo formativo de aquisição de saberes. Movimento. Revista de Educação Física da UGRGS, 22(2), 509-521. doi: https:/doi.org/10.22456/19828918.55346

Sanz, D.R., Fuentes, J.P. \& Villar, F.A. (2004). La formación del entrenador de tenis. In torres, G., Carrasco, L. (Eds.), Investigación en deportes de raqueta: tenis y bádminton (pp: 341364). Múrcia: Universidad Católica San Antonio editora.

Silva, S.G., Minatto, G., Fares, D. \& Santos, S.G. (2011). Caracterização da Pesquisa (Tipos de Pesquisa). In S.G. Santos (Ed.). Métodos e Técnicas de Pesquisa Quantitativa Aplicada à Educação Física (pp. 67-73). Florianópolis: Tribo da Ilha.

Stoszkowski, J. \& Collins, D. (2016). Sources, topics and use of knowledge by coaches. Journal of Sports Sciences, 34(9), 794-802. doi: https://doi.org/10.1080/02640414.2015.1072279

Taylor, W. \& Garrat, D. (2013). Coaching and professionalization. In P. Potrac, W. Gilbert e J. Denison (Eds.), Routledge Handbook of Sports Coaching (pp. 27-39). London: Routledge.

Trudel, P. \& Gilbert, W. (2013). The role of deliberate practice in becoming an expert coach: Part 3 - Creating optimal settings. Olympic Coach Magazine, 24(2), 15-28. Recuperado de http://www.teamusa.org/About-the-USOC/Athlete-Development/Coaching-

Education/Coach-E-Magazine

Trudel, P., Gilbert, W. \& Werthner, P. (2010). Coach Education Effectivenes. In: J. Lyle \& C.J. Cushion (Eds.). Sports Coaching: Professionalization and Practice (pp. 135-152). London: Elsevier.

Walker. L.F, Thomas, R. \& Driska, A.P. (2018). Informal and nonformal learning for sport coaches: A systematic review. International Journal of Sports Science \& Coaching, 13(5), 694-707. doi: https://doi.org/10.1177/1747954118791522 